\title{
A OBSOLESCÊNCIA PROGRAMADA E PSICOLÓGICA COMO FORMA DE BIOPODER: PERSPECTIVAS JURÍDICAS DO CONSUMISMO
}

\author{
Mariana Ribeiro Santiago ${ }^{1}$ \\ Sinara Lacerda Andrade ${ }^{2}$
}

\begin{abstract}
Resumo
O presente trabalho tem o escopo de enquadrar a obsolescência programada e psicológica como mecanismo de biopoder, demonstrando que tais práticas exercem determinado controle sob o consumidor, retirando-lhe, por vezes, a capacidade cognitiva de decidir o que, quando e se necessário consumir. O referencial teórico para analise das práticas abusivas foi a sociedade de consumo. Evidenciando que todas as espécies de obsolescência são consideradas contrárias ao direito das relações de consumo, o presente estudo demonstrou que não há necessidade da criação de novas leis a fim de coibir a prática. $\mathrm{O}$ trabalho foi desenvolvido utilizando-se o método dedutivo de pesquisa com amparo na legislação brasileira codificada e extravagante, que demonstraram ser suficientes para o enfrentamento da obsolescência programada.
\end{abstract}

Palavras-chaves: Biopoder; Obsolescência programada; Obsolescência psicológica; Aumento do consumo.

\section{INTRODUÇÃO}

A proposta do presente trabalho é analisar a obsolescência programada e psicológica como formas de mecanismos de controle, pesquisando seus reflexos no aumento do consumo e demonstrando como a legislação pátria poderá atuar de maneira preventiva a essa prática, nociva para as relações de consumo.

Para tanto, aborda-se, no primeiro capítulo, o biopoder, em linhas gerais, como forma de mecanismo de controle, elucidando a sua genealogia histórica, sua efetiva implementação por meio das instituições de sequestro, como propôs Michel Foucault (1974) e sua versão pós-moderna, na qual é exercido por meio do conhecimento e da construção de novos saberes.

Após isso, no segundo capítulo, analisam-se as alterações que as relações de consumo sofreram após o período da revolução industrial, e o resultado sociológico da globalização econômica, com o surgimento da sociedade de consumo e da prática da obsolescência programada e psicológica, como forma de biopoder.

\footnotetext{
${ }^{1}$ Doutora em Direito pela Pontifícia Universidade Católica de São Paulo - PUCSP. Professora do Programa de Mestrado em Direito da Universidade de Marília - UNIMAR. E-mail: mari.santiago@terra.com.br

${ }^{2}$ Mestranda em Direito pela Universidade de Marília - UNIMAR. E-mail: mariana@nbsadvogados.com.br vol.09, no. 04, Rio de Janeiro, 2016. pp. 1771-1786 
Já o terceiro capítulo é dedicado a demonstrar que a obsolescência programada e psicológica está em dissonância com os princípios da função social e solidária da empresa, sendo apontadas as possibilidades jurídicas que a legislação pátria pode oferecer, a fim de coibir a aludida prática.

Objetiva-se com o presente estudo apresentar uma resposta efetiva à prática da obsolescência programada e psicológica, num esforço de pesquisa que envolve interdisciplinaridade entre a ciência do Direito, Sociologia e Psicologia.

O estudo se justifica pelo impacto da prática da obsolescência, ao estimular o consumismo, em termos de sustentabilidade ambiental, econômica e social, o que gera prejuízo para a sociedade e, inclusive, para as gerações futuras, havendo, ainda, pouca doutrina jurídica explorando a matéria.

Por fim, para a concretização da pesquisa em tela, utilizar-se-á o método dedutivo, associado aos instrumentos de pesquisa bibliográfica, partindo-se da análise do código de defesa do consumidor e da Lei de Política Nacional de Resíduos Sólidos, regras gerais, visando alcançar a compreensão dos casos específicos de obsolescência.

\section{O BIOPODER COMO MECANISMO DE CONTROLE SOCIAL}

Considerado um dos filósofos mais influentes da modernidade, Michel Foucault estudou o saber, o poder e o homem, ajudando a elucidar o papel das instituições sociais como hospícios, hospitais e escolas. O objeto de seu estudo foram as formas de controle exercidas pelas instituições sociais e seus processos disciplinares.

O conceito de Foucault de homem enquanto objeto foi essencial para o desenvolvimento de sua teoria na idade moderna. Submetidos à ação externa, mentes e corpos humanos poderiam ser moldados por diversas instituições sociais. Ao mesmo tempo em que se firmavam várias instituições sociais de proteção e assistência aos cidadãos, como família, hospitais escolas e prisões, nelas também se inseriam mecanismos de controle baseados na ameaça de punição. Tais mecanismos foram denominados de tecnologia política, com poderes de controlar tempo, espaço e informações.

O poder é exercido e manifestado, inclusive, por animais irracionais, nas espécies biológicas, pois, instintivamente, o animal mais violento exerce o poder sobre os demais, submetendo-os a seu domínio, desde a pré-história. Ao homem mais forte e astuto é concedida a prerrogativa de exercer o poder e, consequentemente, decidir sobre o destino dos seus pares.

Já na antiguidade clássica, o poder era unicamente a manifestação da vontade dos deuses. Essa vontade era consubstanciada na figura do oráculo, que era o intermediário humano, sacerdote ou sacerdotisa, detentor do poder, escolhido para transmitir as mensagens dos deuses para os mortais. 
Michel Foucault dispõe que foi no Império Romano que primeiramente se vislumbrou a existência de um poder oculto e inconsciente, realizado por meio da intervenção estatal.

Na primeira conferência, Crise de la medicine ou crise de l'antimédicine? (Foucault, 1976/2001a), Foucault aborda um tema que será retomado mais tarde, em outros trabalhos: a relação entre o pastorato ${ }^{1}$ cristão e o governo dos homens. O cristianismo, desde o Império romano, fez da alma um dos objetivos da intervenção do "Estado", já que se propôs a cuidar das almas e salvá-las. Se até o século XVIII as teocracias europeias incluíam entre suas tarefas a salvação das almas, a partir daí, começa a ser preparado e construído o regime sob o qual vivemos hoje, uma "somatocracia". "Nós vivemos sob um regime para o qual uma das finalidades da intervenção estatal é o cuidado do corpo, a saúde corporal, a relação entre doença e saúde etc." (MARTINS, JUNIOR, 2009, p. 158).

Com a queda do Império Romano, houve o enfraquecimento do cristianismo. Sendo assim, o poder de "salvar as almas", que outrora era exercido pela igreja, passou a ser encargo do Estado. A metáfora "salvar as almas" persiste no período moderno, mas, dessa vez, o enfoque passar a ser a saúde e o bem-estar da população.

Na modernidade, com o sistema econômico mercantilista, a vida passa a ser preocupação do Estado. A intervenção Estatal, dessa vez, consubstancia-se na intervenção médica, ampliada para um nível populacional. O Estado passa a trabalhar efetivamente com a prevenção de doenças da população, através de uma incisiva medicalização, tendo como finalidade essencial protegê-la e preservá-la.

No mercantilismo, a população é o elemento fundamental da riqueza e da potência estatal, enquanto força que produz riqueza. Investir na prevenção de doenças significava garantir uma população saudável e, por consequência, uma mão de obra proficua e capaz de produzir mais riquezas para o Estado. Para melhor diagnosticar e identificar quais as doenças essa população poderia ser acometida, era preciso efetivamente repartila e distribuí-la, para melhor controla-la. Nesse contexto, originam-se as primeiras noções de biopoder.

A constante vigilância, contudo, não era a única preocupação do Estado. Para além de vigiar, era preciso construir um sistema de poder capaz de moldar o homem, a fim de torná-lo passivo, útil e disciplinado. Michel Foucault chamou esse processo de poder disciplinar. O poder disciplinar é, antes de tudo, uma forma de organizar o espaço físico e utiliza uma técnica que busca separar, dividir, para melhor controlar.

No século XVIII, houve uma grande reestruturação das cidades. Nesse sentido, observou-se a instalação de um plano sanitário que previa moradias mais adequadas, investimentos na saúde pública e a criação de hospícios, hospitais e escolas, enquanto instituições terapêuticas, cujo objetivo seria promover uma educação médica, voltada para a prevenção de doenças.

Inconscientemente, entretanto, tais instituições possuíam, como escopo final, dividir a população. Com essa sociedade segmentada, tornava-se mais fácil ao Estado fiscalizar o individual, bem como controlar o coletivo. Dessa feita, a vida tona-se objeto de governo. Essa política da medicalização aumenta a força do Estado e, ao mesmo tempo, mantém a ordem social. 
O biopoder como forma de mecanismo de controle já era uma preocupação de Michael Foucault em 1974, quando, no período ditatura militar, ministrou, no estado do Rio de Janeiro, três conferências no Instituto de Medicina Social, o que se nota também em 1976, quando da publicação do artigo La Politique de la santé au XVIII siècle ${ }^{3}$.

Ao estudar o papel das escolas na idade moderna, Michael Foucault vislumbrou ações de vigilância e adestramento do corpo e da mente, formas de exercer o poder e produzir um determinado tipo de sociedade. Nesse sentido, as escolas, assim como os hospitais, quartéis e prisões, eram vistos como "instituições de sequestro", pois os indivíduos seriam retirados do seu espaço social natural e permaneceriam internados nessas instituições, durante um determinado lapso de tempo, a fim de moldar sua conduta, disciplina e comportamento.

Nesse contexto, "a disciplina é um tipo de organização do espaço. É uma técnica de distribuição dos indivíduos através da inserção dos corpos em um espaço individualizado, classificatório e combinatório" (MACHADO, 2009, p. 173). Sendo assim, seria um instrumento de dominação e controle, dedicado a excluir ou domesticar comportamentos divergentes.

Contudo, há que se ressaltar que, embora a ideia de poder disciplinar remeta-nos a imposição de força por meio da coação e disciplina, segundo as conjecturas de Michel Foucault, este não seria imposto de maneira abrupta, violenta ou explícita, mas de forma inconsciente, oculta e sutil, a fim de que não seja notado e, sobretudo, por já existirem na história da humanidade métodos violentos que fracassaram.

Nessa linha, afirma o próprio Michel Foucault:

Esses métodos que permitem o controle minucioso das operações do corpo, que realizam a sujeição constante de suas forças e lhes impõe uma relação de docilidade-utilidade, são o que podemos chamar 'disciplinas'. Muitos processos disciplinares existem há muito tempo: nos conventos, nos exércitos, nas oficinas também. Mas as disciplinas se tornaram no decorrer dos séculos XVII e XVIII formulas gerais de dominação. Diferentes da escravidão, pois não fundamentam numa relação de apropriação dos corpos; é até a elegância da disciplina dispensar essa relação custosa e violenta obtendo efeitos de utilidade pelo menos igualmente grandes (FOUCAULT, 2010, p. 133).

Para justificar esse processo, Michael Foucault utilizou como exemplo a ideia do filósofo inglês Jeremy Benthan (1748-1832), o panóptico, a fim de explicar como seria possível manter, o controle de um poder central sobre uma população a ele subordinado. O panóptico simboliza um local onde se poderia ver, sem ser visto. Todas as pessoas que estariam no entorno dessa estrutura de poder poderiam ser vistas, sem ver. É uma modalidade de construção de poder, que propõe a ideia de um poder absoluto.

De fato, a vida em sociedade demanda controle e disciplina. Ocorre que é imprescindível analisar e delimitar até onde essa vigilância deve ir. Se em outro momento histórico, como já visto, o poder consubstanciavase pela força, sofrimento, físico e tortura, atualmente ele não é mais identificado, não é exercido pelo rei ou pelo carrasco, não possui um "rosto". Ao contrário, o poder hoje está em todos os lugares, internet, sistema de 
educação, câmeras de vigilância e inclusive no olhar do outro indivíduo sobre nós. Quanto mais escondido e disfarçado, mais eficiente é o poder. Olhá-lo de frente, saber como atua, contudo, é uma maneira de diminuir sua força.

Como é sabido, durante um longo período da história, os castigos eram realizados em praça pública, pois seu escopo era que servissem de exemplo a outros transgressores e evitassem, assim, o cometimento de novos delitos. Contudo, com o desenvolvimento humano e os ideais iluministas, as penas em praças públicas gradativamente deixaram de existir, surgindo as prisões como uma forma de humanizar a pena, levando o suplício para longe dos olhos da sociedade.

Ocorre que, atualmente, o poder não se encontra mais centralizado. O poder é uma rede de relacionamentos, está em todos os lugares e em todas as classes sociais. Sendo assim, é impossível que o poder possua tão somente uma fonte controladora, pois há sempre relações de poder, mesmo que de forma oculta. $\mathrm{Na}$ pós-modernidade o poder não se manifesta somente por meio de uma ação opressora, o poder encontra-se difundido e é exercido simultaneamente em várias direções, em diferentes níveis sociais. O exercício do poder está intimamente ligado a um determinado conhecimento, ou seja, o poder é exercido por meio do "saber". Logo, não existe relação de poder que não venha acompanhada da criação de um saber, de um determinado conhecimento (MOSÉ, 2011,2min34s).

Da mesma forma que os novos saberes se consubstanciam em novas formas de poder, é também por meio da sabedoria que se abre um espaço no cognitivo individual para que, por meio da busca pelo conhecimento, o homem possa compreender o que efetivamente não deseja e, assim, por meio de um processo dialético, possa pensar e até criar outras possibilidades para o meio social em que vive.

Nesse contexto, conclui-se que, se é impossível permanecer imune à dominação representada por certos padrões de pensamento e comportamento ou se escapar completamente das relações de poder. É absolutamente viável, por outro lado, criar-se novos saberes e desvincular-se de uma estruturada rede de dominação cognitiva.

A compreensão da dinâmica do biopoder, ora proposta, como forma de controle social, mostra-se profundamente aplicável na análise das relações de consumo, no paradigma da modernidade liquida, preconizada por Bauman, era marcada pelo fenômeno do consumismo e suas mazelas, conforme analisaremos a seguir.

\section{O BIOPODER E SUA INFLUENCIA NO AUMENTO DO CONSUMO, ATRAVÉS DA OBSOLESCÊNCIA}

Após os seus três estágios - capitalismo comercial, industrial e financeiro - e inúmeras crises, o capitalismo ainda persiste como sistema econômico vigente, com alguns desdobramentos, em virtude da globalização e inserção de novas tecnologias na sociedade contemporânea. Para que tal sistema econômico subsista, contudo, é 
necessário que haja um aumento constante na velocidade de produção, distribuição e consumo de bens e serviços.

Nesse contexto, torna-se necessário, para a sobrevivência do sistema, estabelecer alguma medida a fim de aumentar tanto a velocidade da produção como a de consumo. A solução historicamente encontrada pelos fabricantes capitalistas foi tornar a vida útil dos produtos propositalmente menor.

A durabilidade, que outrora era um requisito essencial tanto para o consumidor, como também para a permanência do produto no mercado, hoje é um empecilho à economia capitalista. Somando-se a isso, ressalta-se que o consumidor permanece na ávida expectativa de adquirir com frequência os novos produtos disponíveis no mercado de consumo.

Analisando tal contexto, Jean Baudrillard afirma:

Vivemos o tempo dos objetos: quero dizer que existimos segundo o seu ritmo e em desconformidade com a sua sucessão permanente. Atualmente, somos nós que os vemos nascer, produzir-se e morrer, ao passo que em todas as civilizações anteriores eram os objetos, instrumentos ou monumentos perenes, que sobreviviam às gerações humanas (BAUDRILLARD, 2007, pp. 15-16).

Diante desse quadro, forma-se uma parceria inconsciente, porém, economicamente muito frutífera, entre fornecedores e consumidores, a qual redunda na obsolescência programada e psicológica.

A preocupação em analisar a obsolescência programada partiu de Vance Packard, que em sua obra, a "Estratégia do Desperdício", dedicou-se a estudar as bases da economia crescimentista de consumo, essencialmente fundada na obsolescência programada (PACKARD, 1965, p. 21).

A obsolescência programada é empregada para descrever as mais diversas técnicas adotadas para limitar artificialmente a durabilidade de produtos manufaturados com o objetivo de estimular o consumo repetitivo (SLADE, 2006, p. 5). De tal modo, é possível defini-la como a redução artificial da vida útil dos produtos, ou seja, a diminuição da durabilidade dos bens de consumo, a fim de induzir o consumidor a adquirir produtos substitutos antes do tempo necessário e, por consequência, com mais frequência do que o normal.

Historicamente, a primeira vítima da obsolescência programada foi a lâmpada. Os protótipos primários foram criados com máxima durabilidade e resistência, possuindo um filamento capaz de durar até 2.500 horas. Cosima Dannoritzer (2011,17min33s) aponta em seu documentário que há registros de que, em 1924, surgiu o primeiro cartel do mundo, denominado Phoebus, composto por fabricantes dos Estados Unidos e da Europa, com o objetivo de reduzir a durabilidade das lâmpadas para 1.000 horas, obrigando os consumidores a adquirirem novas lâmpadas, e aumentando, assim, o índice de venda e a margem de lucros.

Nos anos 50 a obsolescência programada surge novamente, contudo, com uma diferença fundamental:

Não havia mais a necessidade de fomentar o consumo, e as empresas passaram a seduzir o consumidor por meio do marketing e do designer. $\mathrm{O}$ enfoque americano era criar consumidores frequentemente insatisfeitos com o produto que desfrutavam, desejando sempre o modelo mais recente. A felicidade somente seria conquistada através da satisfação mutável dos desejos humanos, por meio do consumo ilimitado (DANNORITZER, 2011, $17 \min 33 \mathrm{~s})$. 
Nesse contexto, a economia crescimentista determinava estratégias cujo escopo era estimular o consumo, como uma busca incessante pela felicidade, incutindo no subconsciente social, numa total demonstração da feição contemporânea do biopoder, que: sempre há espaço para adquirirmos mais coisas, cultivando a ideia do excesso e abundância; e o progresso ocorreria somente pelo exercício de descartar determinados bens, o que fomenta a cultura do desperdício.

A obsolescência tornou a sociedade moderna viciada em produtos novos, o que a sociologia denomina de "neofilia", ao contrário das sociedades pré-modernas, que desconfiavam do novo. A "moda" no período medieval, por exemplo, pouco mudou ao longo de mil anos, sendo o vestuário considerado apenas uma questão de necessidade. Em conclusão, pode-se afirmar que a obsolescência foi desenvolvida não apenas para o produto, mas também para as nossas mentes, no intuito de intencionalmente nos manter constantemente insatisfeitos (BOTSMAN e ROGERS, 2011, pp. 28-30).

Tal fim se alcança pela prática das obsolescências programadas: de função, qualidade e desejabilidade; pelo caos planejado, fazendo com que as pessoas percam a noção do valor real dos produtos; pelas vendas a crédito; por meio do hedonismo para as massas; e, por fim, pelo aumento populacional.

Para Zygmunt Bauman, esta economia que dita as regras sociais na sociedade de consumo se alimenta do movimento das mercadorias e é considerada em alta quando o dinheiro muda de mãos rapidamente. Sempre que isso acontece, alguns produtos de consumo estão viajando para o depósito de lixo. Para este tipo de economia, o foco anterior da sociedade de produtores (de apropriação e acumulação) prenuncia a pior das preocupações, a estagnação, a menos que a aquisição seja complementada pelo impulso de desfazimento e descarte. Então, como visto, para atender essas novas necessidades, a economia do consumo tem de se basear no excesso e no desperdício (BAUMAN, 2008, pp. 51-52).

Em se tratando da cultura do desperdício, a obsolescência programada cumpre com maestria seu papel, fazendo com que os produtos sejam descartados, mesmo que ainda cumpram com a finalidade que deveriam ser destinados, ocasionando assim, a rápida circulação do dinheiro.

Mostra-se necessário elucidar que existem três maneiras distintas para um produto se tornar deliberadamente obsoleto, ou seja, três modalidades de obsolescência: pela qualidade, pela função ou pela desejabilidade (MORAES, 2013, p.59).

A obsolescência programada de qualidade ocorre quando o fabricante intencionalmente projeta o tempo de vida útil do produto, desenvolvendo técnicas ou materiais de qualidade inferior, antevendo sua quebra ou desgaste para redução de sua durabilidade e aumento dos lucros e das vendas (PACKARD, 1965, p. 51).

Esta primeira espécie de obsolescência programada foi registrada a priorisomente nas lâmpadas elétricas, mas por um breve período de tempo. Seu ápice é atingido no século XX, com a inauguração da sociedade de consumo e a inserção das novas tecnologias. Têm-se como exemplo o surgimento dos automóveis que detinham vol.09, nº. 04, Rio de Janeiro, 2016.pp. 1771-1786 1777 
a tecnologia de partida elétrica: todos os outros modelos sem a nova tecnologia tornaram-se obsoletos, gerando uma rápida substituição destes pelos novos modelos, fomentado o mercado de automóveis (MORAES, 2013, p. 59).

Em contrapartida, a substituição de produtos quase sempre implica em exploração de novos recursos naturais, que são fontes não renováveis e produzem novos resíduos, que serão descartados no meio, intensificando ainda mais, a crise socioambiental.

Já a obsolescência programada adiada de função pode ser compreendida como uma subespécie da obsolescência programada de qualidade. Segundo, Schewe e Smith, (Apud MORAES, 2013, p. 60) a obsolescência adiada, ocorre quando o fabricante tem condições de introduzir melhorias por meio de novas tecnológicas nos bens de consumo, mas somente o faz quando o produto se desvaloriza e sua demanda no mercado declina.

Sendo assim, é fato que a obsolescência adiada pode ser enquadrada como um tipo de obsolescência planejada de qualidade, visto que, a fabricante deliberadamente lança no mercado um produto com qualidade tecnológica inferior ao patamar já alcançado nas pesquisas, tornando-o indubitavelmente obsoleto pela introdução das melhorias tecnológicas já desenvolvidas antes mesmo do seu lançamento no mercado.

Moraes (2013, p. 61) elucida que tal estratégia é amplamente utilizada pela indústria contemporânea, mostrando-se extremamente perniciosa e abusiva, pois não corresponde com direito do consumidor em ter acesso a produtos de melhor qualidade e melhor tecnologia disponível, assim como não observa o princípio da sustentabilidade socioambiental.

Por fim, tem-se como última modalidade a obsolescência por desejabilidade. Desejar, segundo o Dicionário Aurélio da Língua Portuguesa, é o ato de querer; ter empenho em; apetecer; ambicionar, sendo assim, desejar, nada mais é do que cobiçar (FERREIRA, 2004, p. 640).

Na teoria psicanalítica de Sigmund Freud, o princípio de prazer é o desejo de gratificação imediata, tal desejo conduz o indivíduo a buscar incessantemente o prazer como mecanismo de compensação à dor, ou seja, o desejo é o princípio de tudo (PSICANALÍTICAS, 2015).

Nesse contexto sensorialmente analítico, a obsolescência psicológica ocorre quando se utiliza mecanismos para modificar o design dos produtos como forma de induzir, instigar, seduzir os consumidores a gastarem reiteradamente, ou seja, é uma forma de tornar obsoleto o produto, não tecnicamente, mas torna-lo antiquado tão somente na psique do consumidor.

Assim, os consumidores são condicionados a associar o novo com o melhor e o velho com o pior e obsoleto. Estilo, aparência e forma dos produtos, tornam-se iscas indispensáveis a fim de pescar o consumidor, que passa a desejar sempre o novo. É o design que dá a ilusão de mudança por meio da criação de um estilo. Essa obsolescência faz o consumidor sentir-se desconfortável ao utilizar um produto que se tornou obsoleto em sua vol.09, nº. 04, Rio de Janeiro, 2016.pp. 1771-1786 1778 
forma, devido aos novos estilos dos modernos modelos.

Um exemplo recente de obsolescência psicológica foi a tática promovida pela empresa Apple, que, embora seja conhecida mundialmente por ser uma empresa "verde", lançou no território nacional o iPad 4, poucos meses depois de ter colocado em circulação o iPad 3 no Brasil. Os usuários desse produto, diante do lançamento de uma nova versão que não apresentava consideráveis diferenças técnicas, mas exibia novo design, notaram que seu produto recém-adquirido, tornou-se obsoleto. Tal fato ensejou uma ação judicial, objetivando a substituição imediata do produto obsoleto (DANNORITZER, 2011, 17min33s).

Atualmente os fabricantes tentam eximir-se da responsabilidade pela obsolescência psicológica, transferindo-a ao consumidor, sob o argumento da livre escolha, ou seja, é este quem opta por, substituir um produto "velho", ainda útil, por um mais novo, alegando que não se trada de uma coerção. Por óbvio que se trata de um engodo, pois, embora tenha o consumidor absoluta liberdade para consumir, o sistema lhe impõe situações de exclusão social, mesmo que implícitas, em nítida estratégia de biopoder.

Os resultados de tais condutas são diversos: obsolescência programada; superendividamento; aumento do acúmulo de lixo tecnológico; esgotamento dos recursos naturais e a perda dos valores humanos, originada da busca incansável dos indivíduos para a satisfação dos seus desejos; e, por fim, o famigerado hiperindividualismo pós-moderno.

Como observado, a prática da obsolescência programada e psicológica caracteriza-se por uma irracionalidade ecológica e social, visto que dedica atenção apenas ao aspecto econômico. Todavia, para o real desenvolvimento social sustentável, é necessário que haja preocupação com o bem-estar social da presente e futuras gerações, destinando atenção aos aspectos social e ambiental na mesma proporção do econômico.

Neste sentido, nota-se que o crescimento econômico motivado pelos mecanismos de biopoder consubstanciados na obsolescência programada e psicológica, propiciaram uma inversão de valores e até uma crise humanitária de aspectos internacionais, ratificando, assim, a relevância do tema.

Diagnosticado o problema, faz-se necessário, em consequência, realizar-se um prognóstico por meio dos mecanismos legais que possibilitam a atuação jurisdicional do Estado Brasileiro na questão, ao que nos propomos a seguir.

\section{OS INSTRUMENTOS JURÍDICOS DE CONTENÇÃO DA OBSOLESCENCIA PROGRAMADA E PSICOLÓGICA}

Após inúmeras discussões acerca dos padrões de produção e consumo no contexto social, observa-se a necessidade de elucidar o arcabouço jurídico de contenção às patologias identificadas no presente trabalho, principalmente no que tange à vida útil dos produtos. 
Partindo da base principiológica, observa-se claramente que as formas de obsolescência contrariam a função social e solidária da empresa, bem como a boa-fé objetiva, o que por si só já seria suficiente para considerarmos a prática contrária ao ordenamento jurídico pátrio.

A empresa, em síntese, no sentido econômico, pode ser definida como uma organização de fatores de produção. Está inserida na ordem econômica como agente organizador da atividade produtiva e gestora de propriedades privadas (REQUIÃO, 1978, p. 32).

A esse respeito, vale lembrar a lição de Jaime Santos Briz (1966, p. 26), para quem:

La libertad de industria en sentido amplio (como libertad de creación de empresas y libertad de economía) encierra la libertad de competencia, la libertad de contratación, la de producción y la de consumo ${ }^{4}$.

Dessa forma, pode-se afirmar que limitar a empresa através de sua sociabilidade ou função social significa a democratização e moralização do governo da empresa e a realização de uma conduta que atenda aos superiores interesses do país e da sociedade (WALD, 2003, p. 854).

Maria Helena Diniz (1998, p. 613) define a função social da empresa como:

O exercício pelo administrador da sociedade por ações das atribuições legais e estatutárias para a consecução dos fins e do interesse da companhia, usando do seu poder de modo a atingir a satisfação das exigências do bem comum.

No mesmo sentido, Eduardo Tomasevicius Filho (2003, p. 40) afirma que a função social da empresa constitui um poder-dever por parte do empresário e dos administradores da empresa de harmonizarem as atividades desta com o interesse da sociedade, mediante a obediência de determinados deveres positivos e negativos.

A seu turno, o princípio da solidariedade social, previsto no artigo $3^{\circ}$, I, da Constituição Federal, que sustenta a função solidária da empresa, possui uma conotação diversa, pois agrega uma ideia de que se deve também colaborar, por meio do negócio, para o desenvolvimento da sociedade, numa perspectiva de sustentabilidade, de uma forma positiva, inclusive sob o ângulo das gerações futuras. A função solidária da empresa é aquela que traz uma contribuição valorosa para o desenvolvimento social.

Comentando o art. 3º, I, da Constituição brasileira, José Afonso da Silva (2009, pp. 46-47) assevera:

O que a Constituição quer, com esse objetivo fundamental, é que a República Federativa do Brasil construa uma ordem de homens livres, em que a justiça distributiva e retributiva seja um fator de dignificação da pessoa e em que o sentimento de responsabilidade e apoio recíprocos solidifique a ideia de comunidade fundada no bem comum. Surge aí o signo do Estado democrático de direito, voltado à realização da justiça social, tanto quanto a fórmula liberdade igualdade e fraternidade o fora no Estado liberal proveniente da Revolução Francesa.

Ao tentar precisar o alcance da palavra solidariedade, Paulo Luiz Netto Lôbo (2009, p. 81) afirma que esta,

\footnotetext{
${ }^{4}$ A liberdade de indústria em sentido amplo (como liberdade de criação de empresas e liberdade de economia) encerra a liberdade de competência, a liberdade de contratação e a de consumo (tradução livre).
} 
Como categoria ética e moral que se projetou para o mundo jurídico, significa um vínculo de sentimento racionalmente guiado, limitado e auto-determinado que impõe a cada pessoa deveres de cooperação, assistência, amparo, ajuda e cuidado em relação às outras. A solidariedade cresce de importância na medida em que permite a tomada de consciência da interdependência social.

A solidariedade social realiza-se, então, como um ato complexo, no qual concorrem o Poder Público e a própria sociedade, apontando a Constituição Federal as diretrizes ideológicas, políticas e jurídicas para sua otimização e implementação, ao acolher os princípios da dignidade humana e do pluralismo social e político (DINIZ, 2007, p. 173).

No tocante ao princípio da boa-fé objetiva, as partes devem se auxiliar mutuamente tanto na celebração quanto na execução dos contratos, comportando-se com lealdade, honestidade e confiança. Daí se conclui que a boa-fé objetiva tem uma função negativa, visando impedir a ocorrência de comportamentos desleais (obrigação de lealdade); bem como uma função positiva, objetivando promover a cooperação entre as partes (obrigação de cooperação) (GOMES, 1999, p. 50).

Na prática, a boa-fé objetiva se observa quando as partes se esforçam em esclarecer todos os fatos relevantes atinentes à contratação, procurando equilibrar realmente as prestações, expressando-se com clareza, preservando os segredos profissionais, mesmo após a extinção do contrato, e agindo de forma a evitar o enriquecimento indevido de uma das partes (AZEVEDO, 2002, pp. 26-27).

Essa conscientização a respeito da necessidade de se observar a boa-fé objetiva nos contratos é essencial para o comércio, pois de outro modo não seria possível a realização de muitos dos negócios modernos, revestidos de grande informalidade, como, por exemplo, as transferências de grandes somas em dinheiro via telefone; as operações da bolsa de valores, que se fecham mediante simples gestos com a mão ou com a cabeça etc. (ALTERINI, 1999, p. 34).

Além disso, sem essa lealdade e confiança exigidas através da boa-fé objetiva enquanto fundamento das relações humanas, não seria viável uma convivência pacífica e próspera, pois preponderaria a discórdia e viveriam os homens em permanente estado de guerra (LARENZ, 1978, pp. 58-59).

Dentro desse quadro da boa-fé objetiva, traçado pelo Código de Defesa do Consumidor, pode-se concluir que os deveres de informação e transparência, a confiança e a proibição da publicidade enganosa são corolários desse princípio, embora alguns autores os apontem como princípios autônomos das relações de consumo.

Neste contexto, Erik Jayme, dispõe que as normas principiológicas, como o artigo $4^{\circ}$ do Código de Defesa do Consumidor, ganharam eficácia e aplicação importante na pós-modernidade por serem normas narrativas:

Na pós-modernidade, os elementos comunicação e narração tomaram a sociedade, as ciências e o direito. A comunicação é um valor máximo da pós-modernidade, associado à 
valorização extrema do tempo, do direito como instrumento de comunicação, de informação, como valorização do passar do tempo nas relações humanas, valorização do eterno e do transitório, do congelar momentos e ações para garantir a proteção dos mais fracos e dos grupos que a lei privilegiar (JAYME, 1995, p. 236).

De forma específica, quando a intenção for dirimir um caso prático envolvendo um conflito da obsolescência programada de qualidade, importante que se observe a Política Nacional de Relações de Consumo, especialmente, no que dispõe o artigo 4ㅇ, I, d, III, IV e VI, bem como a proibição de práticas comerciais abusivas, no que toca colocar no mercado produtos em desacordo com as normas expedidas por órgãos oficiais competentes e/ou pela ABNT - artigo 39, VIII.

O Código de Defesa do Consumidor traz em seu bojo disposições de proteção e defesa do consumidor, dispondo, ainda, em seu Título II, artigos 61 a 80, um rol de crimes contra os consumidores, de natureza exemplificativa. Ante esses dispositivos normativos, consegue-se operar nos casos práticos de obsolescência programada, protegendo de forma direta o consumidor que adquire determinado produto com a vida útil propositalmente reduzida.

Em virtude dessa deficiência na legislação consumerista, que não trata especificamente da obsolescência, há propostas no sentido de alterar o Código de Defesa do Consumidor a fim de estabelecer que a responsabilidade do fornecedor de bens duráveis deverá seguir o critério da vida útil do produto e não mais o da garantia contratual. O tema foi recentemente discutido no I Seminário de Direito Brasileiro de Direito do Consumidor Contemporâneo, ocorrido nos dias 22 a 23 de junho de 2015 (RODAS, 2015).

Com as alterações propostas pelo Ministro do Superior Tribunal de Justiça Luis Felipe Salomão, seria possível proteger o consumidor da obsolescência programada, tornando-a prática abusiva, corrigindo também, as lacunas deixadas pela atual legislação no que tange à responsabilidade dos fornecedores, impondo-os a obrigação de coleta dos produtos obsoletos, gerando um consumo racional e equilibrado, o que estaria em perfeita consonância com a função social e solidária dos contratos de consumo.

Por outro lado, após inúmeras discussões no cenário internacional, envolvendo diversos países acerca do modelo de desenvolvimento usado pela sociedade de consumo, surge na legislação brasileira, a Lei Federal n. ${ }^{\circ}$ 12.305/10, que instituiu a Política Nacional de Resíduos Sólidos, trazendo em seu texto objetivos, princípios e instrumentos que, fundamentados no princípio da sustentabilidade, tem o escopo de ser alicerce jurídico na luta contra a obsolescência programada.

Criada com fundamento no artigo 225 da Constituição da República Federativa do Brasil, a referida lei dispõe princípios que tem por objetivo assegurar a proteção ao meio ambiente, prevendo em seus artigos 30 a 33 a responsabilidade compartilhada entre Poder Público, fornecedores e consumidores sobre o ciclo de vida dos produtos; suas embalagens; forma correta do descarte de pilhas; pneus, óleos, lâmpadas, produtos eletrônicos, cuja finalidade não é somente extirpar a prática da obsolescência programada, mas, também, o dispor sobre o descarte 
do lixo e sua reciclagem.

Quanto à analise pormenorizada de seus dispositivos, observa-se que, embora ainda de forma tímida, a Política Nacional de Resíduos Sólidos preocupou-se em estabelecer uma redução na produção de resíduos sólidos, afastando, por meio de incentivos, a cultura do consumismo.

Importante observar também que o inciso IV, do artigo $6^{\circ}$, da lei em tela, traz de forma expressa o desenvolvimento sustentável como um princípio da Política Nacional de Resíduos Sólidos.

É possível destacar, assim, alguns objetivos contidos na lei como, o estímulo à adoção de padrões sustentáveis de produção e consumo de bens e serviços (artigo 70, III); a prioridade, nas aquisições e contratações governamentais, para bens, serviços e obras que considerem critérios compatíveis com padrões de consumo social e ambientalmente sustentáveis (artigo 7o, XI); o incentivo ao desenvolvimento de sistemas de gestão ambiental e empresarial voltados para a melhoria dos processos produtivos e ao reaproveitamento dos resíduos sólidos, incluídos a recuperação e o aproveitamento energético (artigo 70, XIV); e por fim, o estímulo à rotulagem e ao consumo sustentável.

Observa-se, assim, que a Política Nacional De Resíduos Sólidos, a fim de buscar efetividade, utiliza duas perspectivas: o consumo sustentável, por meio da ideia de padrão de consumo sustentável, disposto no artigo 70, inciso XV e elencado como um objetivo a ser alcançado; bem como, a ecoeficiência, disposta no artigo $6^{\circ}$, inciso V, compreendida pelo conceito de produção sustentável.

Analisando-se a Lei Federal n. ${ }^{\circ}$ 12.305/2010, conclui-se que as noções consumo sustentável demonstram que a responsabilidade quanto à duração e vida útil de um produto deve ser dividida entre os fornecedores, consumidores e Poder Público.

Nessa linha, ao fornecedor caberia o dever de agir rumo a uma produção sustentável, tendo em vista que os recursos ambientais são finitos, devendo produzir bens de qualidade e durabilidade devidamente comprovadas, prestando essas informações aos consumidores. A esses, caberia a responsabilidade de consumir de forma coerente e racional, observando a procedência dos produtos e, principalmente, a real necessidade de adquiri-los. E por fim, o Poder Público encarregar-se-ia de promover a efetividade da presente lei, fiscalizando os preceitos nelas dispostos, a fim de extirpar de todas as relações de consumo a prática da obsolescência programada.

\section{CONCLUSÃO}

Evidenciou-se, no decorrer do estudo, que a submissão social ao consumismo se dá devido a vários fatores, contudo, está fortemente vinculada às formas de controle de poder, denominados por Michel Foucault como biopoder, técnica exercida para limitar a capacidade cognitiva de grande parte da sociedade. 
As práticas da obsolescência programada e psicológica, contudo, são perfeitamente enquadradas como formas contemporâneas de biopoder, que, na modernidade líquida, além de não ser mais reponsabilidade do Estado, não é mais exercido pelas instituições de sequestro, através de vigilância e medo, mas também pelos fabricantes e fornecedores de produtos e serviços, por meio de redes cognitivamente estruturas, que atuam de maneira paulatina e inconsciente, exercendo controle inclusive, sob os desejos dos consumidores, com o escopo exclusivo de aumentar o consumo e a obtenção de lucro.

Nesse contexto, embora não se vislumbre no Código de Defesa do Consumidor, atualmente, disposição específica acerca da obsolescência, tal conduta contraria os princípios norteadores das relações de consumo, devendo ser prontamente coibida pelo Poder Judiciário, com lastro na função social e solidária da empresa; na boa-fé objetiva; nos próprios dispositivos do Código de Defesa do Consumidor que proíbem as práticas e cláusulas contratuais abusivas, bem como a publicidade enganosa e abusiva; e na Lei de Resíduos Sólidos.

Portanto, como demonstrado, o maior entrave à resolução dos conflitos que envolvem a obsolescência programada, atualmente, não é a ausência de positivação normativa, mas a falta de efetividade da legislação existente, que deve ser utilizada no sentido de promover a atuação solidária da sociedade civil, do Estado e do mercado na implementação da sustentabilidade.

\title{
PLANNED AND PSYCHOLOGICAL OBSOLESCENCE AS A FORM OF BIOPOWER: LAW PERSPECTIVES OF CONSUMERISM
}

\begin{abstract}
The present work has the scope of analyzing planned obsolescence and psychological framing as biopower engine, demonstrating that such practices carry out certain control under the consumer, removing him, sometimes, from the cognitive ability to decide what, when and if it is necessary to consume. The theoretical framework for analysis of the abusive practices was the consumer society. Highlighting that all species of obsolescence are considered against the consumption law, the present study has demonstrated that there is no need to create new laws in order to stop that practice. The work was developed using the deductive research method and based in Brazilian legislation codified and extravagant, that proven sufficient to deal with the planned obsolescence.
\end{abstract}

Keywords: Biopower; Planned obsolescence; Psychological obsolescence; Increased consumption.

\section{REFERÊNCIAS}

ALMEIDA, João Flávio de. O discurso da obsolescência: o velho, o novo e o consumo. São Carlos: UFSCar, 2014.

ALTERINI, Atilio Aníbal. Contratos: teoría general. Buenos Aires: Abeledo-Perrot, 1999. 
AZEVEDO, Álvaro Villaça. Teoria geral dos contratos típicos e atípicos. São Paulo: Atlas, 2002.

BAUDRILLARD, Jean. A sociedade de consumo. Lisboa: Edições 70, 2007.

BAUMAN, Zygmunt. Vida para consumo: a transformação das pessoas em mercadoria. Rio de Janeiro: Zahar, 2008.

BOTSMAN, Rachel e ROGERS, Roo. O que é meu é seu: como o consumo colaborativo vai mudar o nosso mundo. Porto Alegre: Bookman, 2011.

BRASIL. Constituição da República Federativa do Brasil. Disponível em: <http://www.planalto.gov.br/ccivil_03/constituicao/constituicao.htm>. Acesso em: 30 jan. 16.

Lei n. ${ }^{\circ}$ 12.305, de 2 de agosto de 2010: institui a Política Nacional de Resíduos Sólidos; altera a Lei no 9.605, de 12 de fevereiro de 1998; e dá outras providências. Disponível em: < http://www.planalto.gov.br/ccivil_03/_ato2007-2010/2010/lei/112305.htm>. Acesso em 30 jan. 16.

Lei $\mathrm{n}^{\circ}$ 8.078, de 11 de setembro de 1990: dispõe sobre a proteção do consumidor e dá outras providências. Disponível em: <http://www.planalto.gov.br/ccivil_03/leis/18078.htm>. Acesso em 30 jan. 16.

BRIZ, Jaime Santos. La contratación privada: sus problemas en el tráfico moderno. Madri: Montecorvo, 1966.

DANNORITZER, Cosima. Comprar, tirar, comprar: la historia secreta de la obsolescencia programada. Produção de Cosima Dannoritzer. [S.l.], Arte France, Televisión Española, Televisió de Catalunya, 2011. (52min18s). Disponível em: <https://www.youtube.com/watch?v=o0k7UhDpOAo>. Acesso em: 02 nov. 15.

DINIZ, Marcio Augusto de Vasconcelos. Estado social e o princípio da solidariedade. Nomos: Revista do Curso de Mestrado em direito da UFC. Fortaleza, v. 26, pp. 171-185, janeiro-junho de 2007.

DINIZ, Maria Helena. Dicionário jurídico. São Paulo: Saraiva, vs. 2-4, 1998.

ENGBRUCH, Werner; DI SANTIS Bruno Morais. A evolução histórica do sistema prisional e a Penitenciária do Estado de São Paulo. Revista Liberdades 2012. Instituto Brasileiro de Ciências Criminais. Disponível em: < https://www.ibccrim.org.br/revista_liberdades_artigo/145-HISTRIA>. Acesso em: 24 Out. 15.

FERREIRA, Aurélio Buarque de Holanda. Novo dicionário Aurélio da língua portuguesa. 3. ed. Curitiba: Positivo, 2004.

FOUCAULT, Michel. Vigiar e Punir: nascimento da prisão. 38 ed. Petrópolis - RJ: Vozes, 2010.

GALLO, Silvio. Governamentalidade democrática e ensino de Filosofia no Brasil contemporâneo. Biopolítica, Governamentalidade e Educação, Sciello. Disponível em: < http://www.scielo.br/scielo.php?pid=S0100$15742012000100005 \&$ script=sci_arttext $>$. Acesso em: 25 out. 15.

GOMES, Luiz Roldão de Freitas. Contrato. Rio de Janeiro: Renovar, 1999.

JAYME, Erik. Considerations historiques et actuelles sur la codification du droit international privé. Recueil des Cours de l'Académie de la Haye, 1995.

LARENZ, Karl. Derecho civil: parte general. Madrid: Revista de Derecho Privado, 1978.

LÔBO, Paulo Luiz Netto. Direito civil: parte geral. São Paulo: Saraiva, 2009. 
MACHADO, Roberto. Foucault, a ciência e o saber. 4. ed. Rio de Janeiro: Jorge Zahar, 2009.

MARTINS, Luiz Alberto Moreira e JUNIOR, Carlos Augusto Peixoto. Genealogia do Poder. Psicologia \& Sociedade. Pontifícia Universidade Católica, 2009, Rio de Janeiro.

MORAES, Kamila Guimarães de. Obsolescência planejada de qualidade: fundamentos e perspectivas jurídicoambientais de enfrentamento. 2013. 274 f. Dissertação (Mestrado) - Universidade Federal de Santa Catarina, Centro de Ciências Jurídicas. Programa de Pós-Graduação em Direito, Florianópolis, 2013.

MOSÉ, Viviane. Ser ou não ser. Foucault e as relações de poder. Produção e reportagem: Maria Luiza Silveira, Rede Globo de Televisão, Brasil, Produzido em: 07 de mar. 2012. (09min38s). Disponível em: $<$ https://www.youtube.com/watch?v=mKD1Nj15ZMk $>$. Acesso em: 24 jan. 16.

NETTO, Domingos e al. (Coord.). O novo Código Civil: estudos em homenagem ao Prof. Miguel Reale. São Paulo: LTR, pp. 838-855, 2003.

PACKARD, Vance. Estratégia do desperdício. São Paulo: Ibrasa, 1965.

PSICANALÍTICAS, Núcleo Brasileiro. Sigmunt Freud. Disponível em: <http://www.nucleodepesquisas.com.br/biografias/sigmund-freud-1856-1939/>. Acesso em: 11 out. 15.

REQUIÃO, Rubens. A co-gestão: a função social da empresa e o Estado de direito. Revista Forense, São Paulo, a. 74, v. 262, pp. 31-39, abr.-jun./1978.

RODAS, Sérgio. CDC deve proteger consumidor da obsolescência programada, diz ministro. Disponível em: < http://www.conjur.com.br/2015-jun-25/cdc-combater-obsolescencia-programada-ministro-salomao>. Acesso em: 17 out. 15 .

SANTOS, Vanessa Sardinha dos. Espécies biológicas. Mundo Educação 2015. Disponível em: <http://www.mundoeducacao.com/biologia/especie-biologica.htm> Acesso em: 22 out.15.

SILVA, José Afonso da. Comentário contextual à Constituição. 6. ed. atual., São Paulo: Malheiros, 2009.

SLADE, Giles. Made to break: technology and obsolescence in America. Cambridge: Harvard University Press, 2006.

TOMASEVICIUS FILHO, Eduardo. A função social da empresa. Revista dos Tribunais. São Paulo, a. 92, v. 810, pp. 33-50, abr. 2003.

WALD, Arnoldo. O empresário, a empresa e o Código Civil. In: FRANCIULLI NETTO, Domingos e alli. (Coord.). O novo Código Civil: estudos em homenagem ao Prof. Miguel Reale. São Paulo: LTR, 2003.

Trabalho enviado em 01 de fevereiro de 2016.

Aceito em 02 de maio de 2016. 